\title{
ÍNDICE DE GOVERNANÇA ELETRÔNICA NOS MUNICÍPIOS: uma análise do estado de Sergipe
}

\author{
1- Rony Klay Viana de Freitas* \\ Mestrando em Administração pela Universidade Federal de Sergipe (UFS), Brasil. \\ ronyfreitas@gmail.com \\ http://lattes.cnpq.br/7286862358688098
}

\section{2- Maria Conceição Melo Silva Luft}

Doutora em Administração pela Universidade Federal de Pernambuco (UFPE), Brasil.

Professora do Programa de Pós-Graduação em Administração da Universidade Federal de Sergipe (UFS), Brasil. ceica@ufs.br

http://lattes.cnpq.br/4838157048357924

Diego Maganhotto Coraiola - Editor Geral
Editor responsável pela submissão:
Tania Margarete Mezzomo Keinert.

Artigo analisado via processo de revisão duplo cego (Double-blind). 


\title{
ÍNDICE DE GOVERNANÇA ELETRÔNICA NOS MUNICÍPIOS: UMA ANÁLISE DO ESTADO DE SERGIPE
}

\section{Resumo}

A proposta central do estudo foi apurar o índice de governança eletrônica dos municípios do estado de Sergipe. O estudo objetivou ainda fazer uma correlação dos resultados com o tamanho (população) dos municípios. Realizou-se uma pesquisa descritiva, com abordagem quantitativa, baseado na métrica proposta por Mello e Slomski (2010). A população do estudo compreendeu os 75 municípios do estado de Sergipe. A amostra intencional e não probabilística contemplou os 40 municípios com até 100 mil habitantes que possuíam websites ativos durante a operacionalização da pesquisa. Os dados do estudo foram obtidos nos portais eletrônicos das prefeituras no período da pesquisa entre de 10/06/2013 a 09/07/2013. Os resultados demonstraram que o menor índice de governança eletrônica apurado foi de 4,415\% e o máximo de 42,146\%, enquanto o índice médio dos municípios em estudo é de 13,431\%, sendo considerado extremamente baixo. Constatou-se ainda que, de modo geral, os municípios com maiores populações possuem melhores índices. Além disso, foi possível verificar que as práticas mais identificadas estão relacionadas com questões técnicas (usuabilidade e acessibilidade) em detrimento das práticas de prestação de serviços públicos e participação cidadã.

\section{Palavras-chave}

Governança eletrônica, Governo eletrônico, Democracia eletrônica, Pequenos municípios.

\section{ELECTRONIC GOVERNANCE IN THE MUNICIPALITIES: AN ANALYSIS OF THE SERGIPE STATE}

\begin{abstract}
The central proposal of this study was to determine the rate of electronic governance of the municipalities in the state of Sergipe. The study also aimed to make a correlation of results with the size (population) of the municipalities. We conducted a descriptive research with quantitative approach, based on the metrics proposed by Mello and Slomski (2010). The study population comprised 75 municipalities of the state of Sergipe. The probabilistic intentional sample included the 40 municipalities with up to 100,000 inhabitants who had active websites while conducting research.The study data were obtained from the homepages of the municipalities during the research period (10/06/2013 to the 09/07/2013). The results showed that the lowest index electronic governance calculated was $4.415 \%$ and the maximum of $42.146 \%$, while the index average of the studied municipalities is $13.431 \%$, considered extremely low. It was also found that, in general, municipalities with larger populations have higher rates. Furthermore, we found that the practices more identified are more related to technical issues (usability and accessibility) to the detriment of the practices public service delivery and citizen participation.
\end{abstract}

\section{Keywords}

Electronic governance, e-government, Electronic democracy, Small municipalities. 


\section{Introdução}

Com a mudança nas relações sociais, percebeu-se o surgimento de uma cultura organizada em torno de meios eletrônicos, incluindo neste sistema o computador como mediador das redes de comunicação (Castells, 1999). Expressões culturais de todos os tipos estão cada vez mais fechadas em formas de mídias eletrônicas. Esse novo cenário, denominado pelo referido autor de sociedade em rede, provocou uma "cultura da virtualidade real".

Castells (1999) propõe a hipótese de que a sociedade em rede, como a estrutura social dominante emergente na era da informação, é organizada em torno de novas formas de tempo e espaço: o tempo atemporal. Desta forma, como todas as transformações históricas, o surgimento desta nova estrutura social é necessariamente ligado à redefinição das bases materiais de vida, do tempo e do espaço. Surgem com isso demandas associadas à conformação de um novo paradigma tecnoeconômico, das tecnologias da informação e comunicação e de uma "nova economia" da Era do Conhecimento (Lastres \& Albagli, 1999).

Essa revolução, com foco em Tecnologias da Informação e Comunicação (TICS), além de transformar as relações comerciais, passou a fazer parte das agendas políticas da Administração Pública. A introdução das TiCs exigiu uma maior eficiência do Estado, que além da transformação dos processos internos organizacionais, passou a ter um maior controle social na exigênciade melhoria na prestação serviços públicos e ampliação de espaços democráticos.

Uma maneira encontrada pelos governos para tais exigências dos cidadãos foi (tem sido) a construção de portais governamentais. De acordo com Pinho (2008), esses novos espaços tem permitido aos governos mostrarem as suas identidades, seus propósitos, suas realizações. Além disso, possibilitam a concentração e disponibilização de serviços e informações, o que facilita a realização de negócios e o acesso à identificação das necessidades dos cidadãos.

Corroborando esse entendimento, para Hilgers e Piller (2011), a construção desses espaços virtuais faz parte da chamada New Public Management, que tem como objetivos essenciais a defesa do cidadão como um cliente de serviços públicos e a orientação dos seus processos internos na direção das expectativas desses clientes. Esse movimento baseia-se em princípios gerenciais voltados a resultados, eficiência, governança e orientação da gestão pública para práticas de mercado (Rezende, 2007).

Nesta direção, o uso estratégico das TICs como viabilizadores desse novo modelo de gestão pública evoluiu para o conceito de Governo Eletrônico. A utilização da internet tem se tornado cada vez mais frequente para a disponibilização de informações de órgãos públicos para os cidadãos no Brasil e em todo o mundo. Outro conceito que foi abarcado pelas novas tecnologias virtuais foi a Democracia Eletrônica, ou e-democracia, que contempla a participação política dos cidadãos nas ações do governo por meio das plataformas virtuais (Torres \& Agune, 2009).

Entretanto, mais recentemente, com a necessidade de abarcar esses conceitos (Governo Eletrônico e Democracia Eletrônica) em um conceito mais abrangente, se passou a utilizar o termo "Governança Eletrônica" para conceituar a aplicação das TICs na governança pública, composto das áreas de administração, serviços eletrônicos (governo eletrônico) e democracia eletrônica (Frey 2002; Holzer \& Kim, 2005; Melo \& Slomski, 2010).

$\mathrm{Na}$ arena acadêmica, alguns estudos têm focado as práticas de Governo com o uso das TICs. Dentre esses estudos, alguns se centram nas práticas de Governo Eletrônico, como é o caso de Araújo e Laia (2004) que pesquisaram as práticas de governo eletrônico nos Estados Brasileiros, Klering e Schröeder (2008) que analisaram iniciativas relacionadas ao desenvolvimento de tecnologias de informação, comunicação e interação, em sites e portais municipais, e Funai e Rezende (2011) que avaliaram os serviços de governo eletrônico oferecidos pelas prefeituras e suas considerações no planejamento municipal.

Outros estudos estão centrados nas práticas de democracia eletrônica: Pinho (2008) analisou os portais dos governos das nove principais capitais dos estados e Distrito Federal, para observar como estes são construídos no tocante a disponibilização de informações de interesse para cidadãos e setores empresariais, e quanto à comunicação com a sociedade, e Raupp e Pinho (2012) que identificaram instrumentos de participação nos portais eletrônicos de câmaras municipais.

Entrementes, mesmo com a importância teórica do tema, são escassos os trabalhos que analisam o contexto geral da governança eletrônica (Mello \& Slomski, 2010). Desta forma, esse estudo busca colaborar para o avanço dessa temática, o qual, de acordo com Mello e Slomski (2010) se encontra na fase embrionária de discussão. 
No contexto da administração pública brasileira, conforme afirmam Mello e Slomski (2010), onde a governança eletrônica é pouco conhecida por profissionais da área e pouco pesquisada, fazse necessário apresentar sua definição e estruturação, demonstrar formas de implantação e de evidenciação e identificar os seus benefícios.

Assim, o estudo parte da premissa do crescimento e popularização da internet, e a implementação de diversas políticas de inclusão digital direcionadas para grupos de pessoas menos favorecidas e nos mais diversos lugares do país. Destaca-se, portanto, a relevância e utilidade da pesquisa que propõe averiguar as práticas de governança eletrônica no nível dos micros, pequenos e médios municípios, que representam, de acordo com o Instituto Brasileiro de Geografia e Estatística (IBGE, 2012a), 94,8\% do total de cidades brasileiras.

Ademais, segundo a Pesquisa de Informações Básicas Municipais (IBGE, 2012a), apresentada pelo IBGE, houve um crescimento significativo na proporção de municípios que dispunham de computadores ligados em rede e com acesso à Internet, sendo mais significativo os com computadores ligados em rede, nas classes de municípios até 100.000 habitantes. De acordo com a mesma pesquisa, no nordeste brasileiro, dos 1.794 municípios, 1.735 estão nesta condição (até 100 mil habitantes) e destes, $1.322(76,2 \%)$ possuem portais eletrônicos na internet. Especificamente em Sergipe, 97,3\% dos municípios possuem até 100 mil habitantes e destes 54,8\%, possuem página na internet.

Além da importância acadêmica, o estudo possibilitará aos gestores públicos municipais apreciar fatores a serem melhorados nas políticas de Governança Eletrônica, e, consequentemente resultará na expansão da participação democrática e melhor prestação de serviços aos cidadãos.

Destarte, a proposta central deste estudo é apurar o índice de governança eletrônica dos municípios do estado de Sergipe. O estudo objetivou ainda fazer uma correlação dos resultados com - tamanho (população) dos municípios. Para consecução dos objetivos, utilizou-se a base metodológica adotada por Mello e Slomski (2010), para propor o Índice de Governança Eletrônica dos Municípios (IGEM), abrangendo as práticas de governo eletrônico e democracia eletrônica.

Assim sendo, a pergunta de pesquisa a qual se baseia esse estudo é a seguinte: qual o índice de governança eletrônica dos municípios do estado de Sergipe?

Para tanto, o artigo está estruturado em cinco seções. Após essa introdução são abordados, no referencial teórico, os conceitos de governança eletrônica, governo eletrônico e democracia eletrônica. A terceira seção aborda o percurso metodológico utilizado na pesquisa. A seção seguinte é composta da descrição e análise dos dados. Finalmente, são apresentadas as considerações finais.

\section{Governança Eletrônica}

A partir da expansão dos conceitos de e-serviços e e-democracia, as TICs passam a ser fundamentais para a gestão pública.Com isso, há uma conversão para forma eletrônica dos diferentes tipos de conhecimentos codificados e informações oferecem a possibilidade de dependência mínima de matéria (Lastres \& Ferraz, 1999). Tal uso das formas eletrônicas e das TICs pela Administração Pública é tanto tratada como governo eletrônico (Ferrer \& Santos, 2004; JaegerNeto, Becker, Luciano \& Testa, 2009) quanto governança eletrônica (Frey, 2002; Holzer \& Kim, 2005; Mello \& Slomski, 2010). Verifica-se, portanto, um conflito conceitual entre governo eletrônico e governança eletrônica, visto que pesquisadores algumas vezes atribuem características diferentes a cada um dos termos, ora tratam os conceitos como sinônimos.

O termo Governo Eletrônico centra-se em uma visão de governabilidade, sinalizando como opera, trabalha e se organiza a sociedade à qual o governo deve assegurar o acesso e a participação em diversas redes de informação. Já a Governança eletrônica, possui um sentido mais amplo e abarca o conceito de governo eletrônico, o qual teria como foco as tarefas gerenciais, além das formas de participação cidadã (e-democracia) que conduzem à interação cidadania-governo. Portanto coaduna-se da ideia de que a governança eletrônica é uma dimensão política mais avançada e engloba tanto as ações de governo eletrônico quanto as políticas de democracia eletrônica (Frey, 2002; Ruediger, 2002; Holzer \& Kim, 2005; Mello, 2009; Mello \& Slomski, 2010; Cunha, Frega \& Lemos, 2011; Janowski, Pardo \& Davies, 2012; Beuren, Moura \& Kloeppel, 2013).

Nesse cenário, Ruediger (2002) analisa ainda que, o governo eletrônico é um potencializador de boas práticas de governança e age como um instrumento de mudança profunda nas estruturas 
de governo, proporcionando mais efetividade, transparência e desenvolvimento, além de prover mais democracia e informações para o cidadão.

A governança eletrônica, um dos componentes da governança, seria o resultado da contribuição da democracia e governo eletrônicos para um contexto maior no qual o governo formula e implementa suas políticas com a participação da sociedade, considerando o papel das tecnologias de informação e comunicação e o ambiente regulatório que determina a atuação dos diversos atores (Medeiros \& Guimarães, 2005).

$\mathrm{Na}$ opinião de Araújo e Laia (2004), a governança é condicionada pela instituição governamental de canais de comunicação e de troca de informações que permitem a participação da sociedade na elaboração, acompanhamento e avaliação de políticas públicas, e pela capacidade da burocracia estatal gerenciar esses canais.

Não obstante, disponibilizar serviços on-line ou promover uma administração pública mais eficiente não é o escopo total da governança eletrônica (Mello, 2009). De acordo com o autor, o canal aberto pelas TIC possibilita um desenvolvimento muito maior na administração pública, em virtude dela ter por finalidade o aumento da participação da sociedade no controle das ações governamentais.

Portanto, a governança eletrônica, também denominada e-governança ou governança digital, corresponde ao modo ou ao processo de conduzir uma sociedade para melhor atingir suas metas e interesses (Frey, 2002; Ruediger, 2002), à maneira como aprimorar a capacidade do Estado de governar e formular suas políticas (Medeiros \&Guimarães, 2005), com foco na utilização das tecnologias de informação na busca da melhor atuação do governo (Mello, 2009). Em outras palavras, a governança eletrônica, refere-se ao modo como a internet pode acrisolar a capacidade do Estado de governar e formular suas políticas (Medeiros \& Guimarães, 2005).

Para Sampaio (2010) essa atuação do governo depende essencialmente de três fatores. Primeiro são necessárias ferramentas digitais que estejam consonantes com as transformações e avanços mundiais. Em segundo lugar, essas ferramentas devem ter efeitos reais no sistema político. Pois, não adianta oferecer diversos canais de participação cidadã, se eles não são levados em conta pelos agentes governamentais. E por último, o mais importante fator está relacionado com a vontade política. Os portais governamentais não serão capazes de realizar essa profunda modificação no Estado, se os governantes não estiverem dispostos a permitir tais alterações.

Em síntese, a necessidade de atendimento dessas três premissas, provocou a ampliação do conceito de Governança Eletrônica, que englobou todas as políticas relacionadas às TICs na governança pública, separando-a nas áreas de administração eletrônica, serviços eletrônicos e democracia eletrônica.

Todavia, para Araújo e Laia (2004), assim como é o pensamento de Mello e Slomski (2010), a fronteira entre essas três dimensões é difícil de ser estabelecida, uma vez que uma mesma solução eletrônica pode estar presente em uma, duas ou em todas as dimensões. Mello e Slomski (2010) consideram que a governança eletrônica inclui o governo eletrônico (prestação de serviços públicos) e a democracia eletrônica (participação cidadã no governo) e que esses dois grupos são representados por cinco subgrupos de práticas: conteúdo, serviços, participação cidadã, privacidade e segurança e usabilidade, conforme figura 1.

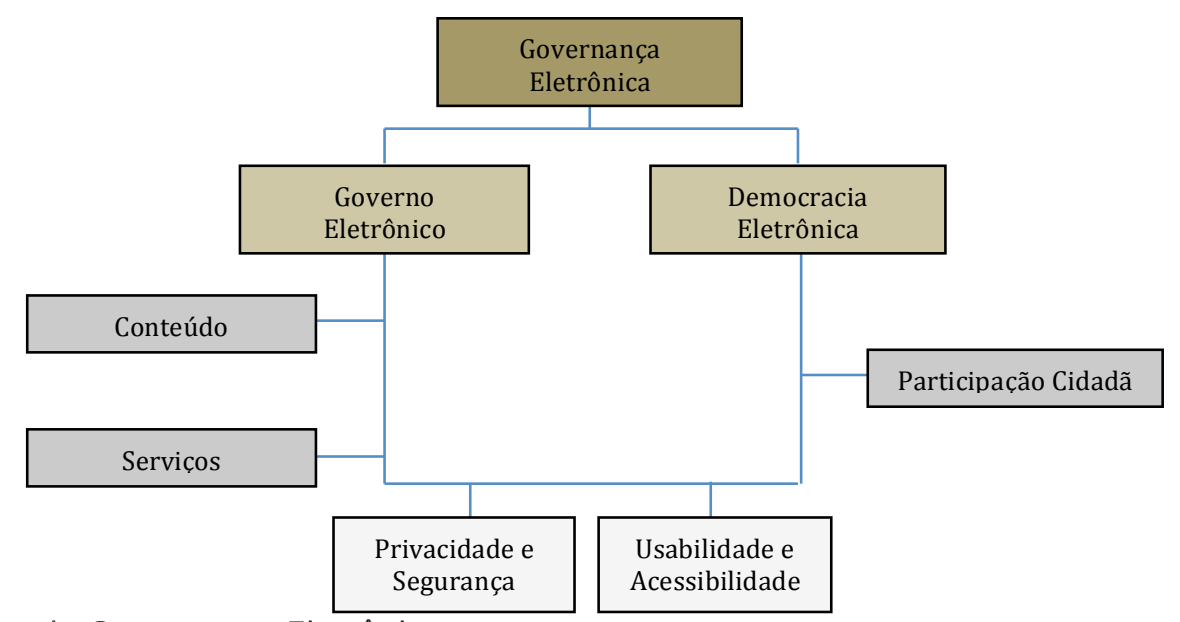

Figura 1 - Componentes da Governança Eletrônica

Fonte: Mello e Slomski, 2010, p. 385. 
Portanto, entende-se que a governança eletrônica tem como áreas ou dimensões: o governo eletrônico (administração eletrônica e prestação de serviços públicos) e a democracia eletrônica (participação cidadã no governo), conceitos que serão abordados a seguir.

\subsection{Governo Eletrônico}

As políticas relacionadas ao Governo Eletrônico expandiram-se no Brasil a partir de 1995, com os movimentos de reforma gerencial do Estado e à expansão da oferta de serviços públicos ao cidadão pela internet. A partir desse momento, em que o governo eletrônico entrou na agenda do primeiro escalão federal, movimentou as estruturas técnicas e políticas dos Estados e Municípios (Mello \& Slomski, 2010).

Preliminarmente, o conceito foi associado apenas com a prestação de serviços por meios digitais. Posteriormente, o termo ampliou-se para uma definição mais abrangente relacionado com a melhoria dos processos de TICS da administração pública, com o uso das TICs no relacionamento com os cidadãos e como propulsor de uma boa governança pública. Deste modo, além de ser uma das principais formas de modernização do Estado, o governo eletrônico permitiu uma nova visão do uso das tecnologias para a prestação de serviços públicos, mudando a maneira pela qual o governo interage com o cidadão, empresas e outros governos (Diniz, Barbosa, Junqueira \& Prado, 2009).

O governo eletrônico, em especial os serviços eletrônicos disponibilizados, beneficia os cidadãos, via transformação dos serviços governamentais e da governança, oferecendo aos governos uma maneira alternativa de servir aos cidadãos e trazer inovação às suas operações internas (Funai \& Rezende, 2011).

Assim, Torres e Agune (2009) definem o Governo Eletrônico como o uso de tecnologias de informação, comunicação e automação para promover melhores serviços à sociedade (cidadãos, empresas, comunidades) e a criação de uma vasta rede de relacionamentos, com eficiência, eficácia e efetividade, por meio de processos que integrem toda a cadeia de valor na oferta destes serviços.

Essa nova forma de oferecer melhores serviços a sociedade provocou um crescimento no número de órgãos e entidades públicas adeptos dessas novas práticas. Embora tenha havido uma grande expansão de governos com presença na internet, a presença das políticas de governo eletrônico ainda estão longe de um patamar satisfatório. A situação dos portais eletrônicos das prefeituras municipais também não é diferente, em pesquisa Klering e Schöeder (2008) verificaram que a grande maioria dos municípios ainda nem mesmo possui site permanente e que seja atualizado de forma sistemática. O estudo de Alexandrini, Piske e Piske (2006) apresentou resultado semelhante, concluindo que governo eletrônico nas administrações municipais pouco se desenvolveu em relação às esferas federal e estadual.

Essa também foi a realidade encontrada por Funai e Rezende (2011), em pesquisa realizada no município de São José dos Pinhais, em que a prefeitura possuía um portal de cunho apenas informacional, e com algumas poucas práticas transacionais de pagamento. Essa conclusão, na visão dos autores demonstra o enorme espaço ainda a trilhar para que haja uma significativa melhoria na qualidade da prestação dos serviços públicos.

Verifica-se, portanto, uma enorme lacuna de atuação dos governos no que diz respeito à utilização dos recursos de Tecnologia da Informação e Comunicação para a promoção da cidadania. Porém, como pressuposto dessa expansão dos governos eletrônicos municipais não basta apenas estar presente na internet. Deve-se atentar para o excesso de informação, que precisa ser organizada e normatizada a fim de se assegurar uma informação inteligente, ou seja, capaz de atender ao demandante de forma oportuna e personalizada (Funai \& Rezende, 2011).

\subsection{Democracia Eletrônica}

Conforme analisam Raupp e Pinho (2012), a necessidade de incorporar a opinião do cidadão à decisão política é uma exigência clássica na história da democracia, porém é na democracia moderna que isso ganha complexidade, devido à ênfase dada ao mecanismo da representação. Nessa mesma linha, Santana Junior, Libonati, Vasconselos e Slomski (2009), o Estado deve estruturar-se para poder fornecer ao cidadão os melhores meios para facilitar e otimizar a sua participação nas decisões governamentais. 
A criação de tais espaços democráticos para os clientes/cidadãos se transforma numa plataforma que pode ser escrita, reescrita e modificada por meio de soluções inovadoras (Hilgers \& Piller, 2011) proposta em um diálogo constante entre governo e sociedade. As novas tecnologias teriam, portanto, potencial para construir uma relação mais estreita entre governo e cidadãos.

Frey (2002) afirma que o uso da internet pelas instituições governamentais, além de ser usada para criar serviços públicos mais personalizados e direcionados ao povo, possibilitaram a criação de redes sociais e novas formas de participação democrática, além de maior interação entre população e Estado. A utilização das novas tecnologias de informação alterou de forma significativa a relação dos cidadãos com o Estado (Araujo, Araújo, Alloufa \& Lopes, 2013), e à medida que as TICs se disseminaram pelo Estado, as próprias relações deste com a sociedade passaram a ser influenciadas (Araujo \& Laia, 2004).

Assim, ao se falar em democracia eletrônica, o que se deseja é a participação política dos cidadãos nas ações do governo (Torres e Agune, 2009). Segundo esses autores, não só cidadãos tem esse canal de comunicação. Empresas também podem colaborar com o governo, por meio de relacionamentos diretos com os agentes de governo - seja registrando suas opiniões, seja atuando mais diretamente nos processos decisórios do governo.

Desse modo, segundo Pinho (2008), a adoção de mecanismos de participação digital implica um governo baseado em maior interação com a sociedade, onde esta compartilha com o governo tarefas até então específicas deste. Em outras palavras, as TICs possuem um enorme potencial democrático, desde que o governo local tenha uma definição política orientada para a participação popular e da transparência, pois o governo pode deixar de oferecer o que não quer mostrar, para nem mencionar o que quer esconder (Pinho, 2008).

Todavia, apesar das benesses, o grau geral de democracia eletrônica promovida pelos municípios por meio dos seus sítios é muito baixo, especialmente em se tratando de oferecer possibilidades para que a sociedade atue nos processos decisórios governamentais, conforme apurou pesquisa de Torres e Agune (2009).

Resultado similar encontrou Pinho (2008) em pesquisa que concluiu que de uma maneira geral, os portais governamentais têm recursos tecnológicos adequados, existem boas condições de navegação, de busca de informações. O que falta é uma predisposição verdadeira para implantação de procedimentos de accountability e participação. Assim, segundo o autor, o problema não é de tecnologia, mas de cultura política, de desenvolvimento político. A tecnologia que poderia ser usada para ampliação das práticas democráticas não é mobilizada nesse sentido.

\section{Procedimentos Metodológicos}

Trata-se de um estudo dedutivo, uma vez que, conforme asseveram Collis e Hussey (2005), o estudo foi desenvolvido em uma estrutura conceitual e teórica que posteriormente foi testada pela observação empírica. No tocante à tipologia relacionada aos objetivos, o estudo caracteriza-se como descritivo, visto que partiu de um objetivo bem definido e a pesquisa foi conduzida para descrevê-lo precisamente (Neuman, 1997).

Para o delineamento de pesquisa utilizou-se da documentação direta (os dados são coletados pelo pesquisador), utilizando-se de um formulário estruturado. De acordo com Beuren, Moura e Kloeppel (2013) essa é forma interessante para operacionalização da pesquisa, visto que os dados estão em fontes públicas e podem ser facilmente coletados. Além disso, os dados são transparentes, permitem uma fácil replicação e são de simples interpretação.

A população do estudo compreendeu os 75 (setenta e cinco) municípios sergipanos. A amostra intencional e não probabilística compreendeu os municípios que possuem até 100 mil habitantes. A razão da escolha desse parâmetro aconteceu para não perder o foco, dentro do contexto geral da governança eletrônica, de observar a implementação de diversas políticas de inclusão digital direcionadas para grupos de pessoas menos favorecidas e nos mais diversos lugares do país.

Para melhor análise dos dados esses municípios foram divididos em três grupos: micro (até 10.000 habitantes), pequenos (de 10.001 até 20.000 habitantes) e médios (de 20.001 até 100.000 habitantes), conforme classificação do IBGE (2012a).

A população da pesquisa representou $97,3 \%$ dos municípios do estado, pois apenas as cidades de Nossa Senhora do Socorro e a capital Aracaju possuem população superior a 100 mil habitantes. Todavia, insta salientar o alto percentual de municípios do estado de Sergipe que ainda não 
possuem portal eletrônico. Entretanto, dos 73 municípios restantes, 33 (17 micro, 10 pequenos e 06 médios) não possuíam ou o portal eletrônico estava em manutenção no momento da coleta de dados, que ocorreu entre 10/06/2013 e 09/07/2013, e foram excluídos do estudo. O restante (27) não possuía página na internet.

Destaca-se que foram feitas no período da coleta de dados três acesso para cada portal em datas diferentes para que os resultados fossem os mais próximos da realidade. Assim, o estudo abrangeu os 40 municípios remanescentes conforme demonstra a tabela 1 .

Tabela 1

Classificação dos municípios da amostra

\begin{tabular}{|c|c|c|c|c|c|}
\hline \multicolumn{2}{|l|}{ Micro } & \multicolumn{2}{|c|}{ Pequenos } & \multicolumn{2}{|c|}{ Médios } \\
\hline Município & População & Município & População & Município & População \\
\hline Arauá & 9495 & $\begin{array}{l}\text { Campo do } \\
\text { Brito }\end{array}$ & 16987 & $\begin{array}{l}\text { Barra dos } \\
\text { Coqueiros }\end{array}$ & 26059 \\
\hline Divina Pastora & 4487 & Carmópolis & 14130 & Boquim & 25727 \\
\hline Macambira & 6492 & Cristinápolis & 16859 & $\begin{array}{l}\text { Canindé de S. } \\
\text { Francisco }\end{array}$ & 25733 \\
\hline $\begin{array}{l}\text { Malhada dos } \\
\text { Bois }\end{array}$ & 3494 & Frei Paulo & 14162 & Capela & 31402 \\
\hline N. S. de Lourdes & 6271 & Japaratuba & 17213 & Estância & 65226 \\
\hline Pedrinhas & 8970 & Japoatã & 12926 & Itabaiana & 88501 \\
\hline Pinhão & 6084 & Maruim & 16478 & Itabaianinha & 39432 \\
\hline Pirambu & 8538 & Moita Bonita & 11038 & $\begin{array}{l}\text { Itaporanga } \\
\text { d'Ajuda }\end{array}$ & 31165 \\
\hline Riachuelo & 9509 & Neópolis & 18493 & Lagarto & 96602 \\
\hline $\begin{array}{l}\text { Santa Rosa de } \\
\text { Lima }\end{array}$ & 3773 & Pacatuba & 13379 & Laranjeiras & 27442 \\
\hline $\begin{array}{l}\text { São Miguel do } \\
\text { Aleixo }\end{array}$ & 3736 & $\begin{array}{l}\text { Riachão do } \\
\text { Dantas }\end{array}$ & 19414 & Poço Redondo & 31614 \\
\hline Siriri & 8169 & $\begin{array}{l}\text { Tomar do } \\
\text { Geru }\end{array}$ & 12858 & Poço Verde & 22287 \\
\hline & & & & Porto da Folha & 27370 \\
\hline & & & & Propriá & 28612 \\
\hline & & & & Tobias Barreto & 48776 \\
\hline & & & & Umbaúba & 23223 \\
\hline
\end{tabular}

Fonte: Estimativa de população divulgada pelo IBGE (2012b) em 31/10/2012.

Para a definição das práticas de governança eletrônica, adotada nesta pesquisa, foram utilizadas as variáveis propostas por Mello e Slomski (2010). Segundo o modelo, a governança eletrônica inclui o governo eletrônico (prestação de serviços públicos) e a democracia eletrônica (participação cidadã no governo) e que esses dois grupos são representados por cinco subgrupos de práticas: conteúdo, serviços, participação cidadã, privacidade e segurança e usabilidade, conforme figura 1 apresentada na seção 2 .

Foram feitas algumas adaptações nas variáveis propostas por Mello e Slomski (2010) para atender a realidade dos municípios que ligeiramente diverge dos estados. Dentre essas modificações estão: a alteração das variáveis referentes à legislação municipal (PCon3, PServ 6), competência tributária (P Serv9, PServ10, PServ14). Além disso, foram inseridas algumas variáveis relacionadas às redes sociais virtuais e uso de dispositivos móveis (PCon14, PUA 13), com base nas perspectivas de Cordeiro, Martins, Santos, Ribeiro \& Petra (2012) e Raupp e Pinho (2012), que destacaram a importância dessas ferramentas na viabilização serviços deinformação que contribuem significativamente na prestação de serviços e democratização da gestão pública. Inseriu-se também uma variável relacionada ao acesso a informação pelos cidadãos (PPC11), de acordo com a lei № 12.527 (2011).

O Apêndice I mostra as 63 dimensões e variáveis da governança eletrônica que foram utilizadas para formação o Índice de Governança Eletrônica dos Municípios (IGEM): 
Na formação do índice, para minimizar o problema de interpretação da escala, conforme propõem Mello e Slomski (2010) inicialmente foi estabelecida uma referência a qual serviu de base para criar a escala utilizada na obtenção dos dados; essa escala leva em consideração as características de cada variável, conforme visualiza-se na tabela 3.

Tabela 3

Escalas de referência

Fonte: adaptado de Mello e Slomski (2010).

\begin{tabular}{|c|l|}
\hline Escala & \multicolumn{1}{c|}{ Descrição } \\
\hline 0 & Prática não identificada \\
\hline 1 & Existem poucas informações sobre a prática \\
\hline 2 & Prática identificada, mas de maneira incompleta \\
\hline 3 & Prática identificada \\
\hline
\end{tabular}

A seguir foram estabelecidos pesos iguais entre os cinco grupos de práticas. Em sequência, considerando o número de práticas por subgrupo, estabeleceu-se a pontuação de cada prática dentro do subgrupo, dividindo o peso dado para o subgrupo pelo seu número de práticas (Tabela 4).

Tabela 4

Procedimentos para elaboração do IGEM

\begin{tabular}{|c|c|c|c|c|c|c|}
\hline \multirow[b]{2}{*}{ Procedimentos } & \multicolumn{5}{|c|}{ Práticas } & \multirow[b]{2}{*}{ Total } \\
\hline & Conteúdo & Serviços & $\begin{array}{l}\text { Participação } \\
\text { Cidadã }\end{array}$ & $\begin{array}{c}\text { Privacidade } \\
\text { e } \\
\text { Segurança }\end{array}$ & $\begin{array}{l}\text { Usabilidade e } \\
\text { Acessibilidade }\end{array}$ & \\
\hline $\begin{array}{l}\text { Peso igual entre os } \\
\text { grupos (a) }\end{array}$ & 20 & 20 & 20 & 20 & 20 & 100 \\
\hline $\begin{array}{l}\text { Número de práticas } \\
\text { por subgrupo (b) }\end{array}$ & 14 & 16 & 11 & 8 & 14 & 63 \\
\hline $\begin{array}{l}\text { Pontuação de cada } \\
\text { prática dentro do } \\
\text { subgrupo }(a / b)\end{array}$ & 1,429 & 1,250 & 1,818 & 2,500 & 1,429 & \\
\hline $\begin{array}{l}\text { Pontuação para } \\
\text { resposta } 0\end{array}$ & 0 & 0 & 0 & 0 & 0 & \\
\hline $\begin{array}{l}\text { Pontuação para } \\
\text { resposta } 1\end{array}$ & 0,476 & 0,417 & 0,606 & 0,833 & 0,476 & \\
\hline $\begin{array}{l}\text { Pontuação para } \\
\text { resposta } 2\end{array}$ & 0,952 & 0,833 & 1,212 & 1,667 & 0,952 & \\
\hline $\begin{array}{l}\text { Pontuação para } \\
\text { resposta } 3\end{array}$ & 1,429 & 1,250 & 1,818 & 2,500 & 1,429 & \\
\hline
\end{tabular}

Fonte: elaboração dos autores, com base em Mello e Slomski (2010).

Após a aplicação dos critérios acima mencionados, o IGEM pode ser representado pela seguinte equação matemática:

\section{em que:}

M = Município;

j = subgrupos de práticas;

\begin{tabular}{|c|c|c|}
\hline $5 \mathrm{Nj} \quad \mathrm{j}$ & & $\mathrm{Nj}$ = número de práticas do tipo j; \\
\hline $\mid G E M=M$ & $\sum \mathrm{Pi}(\mathrm{M})$ & $1 \mathrm{Pi}(\mathrm{E})=$ Peso PConi do Município $\mathrm{M} ;(\mathrm{i}=1 \ldots, \mathrm{N} 1) \quad(\mathrm{N} 1=14)$ \\
\hline & $j=1 i=1$ & 2Pi $(E)=$ Peso PSeri do Município $M ;(i=1 \ldots, N 2)$ \\
\hline & & 3Pi $(E)=$ Peso PPCi do Município $M ;(i=1 \ldots, N 3)$ \\
\hline & & $4 \mathrm{Pi}(\mathrm{E})=$ Peso PPSi do Município $\mathrm{M} ;(i=1 \ldots, \mathrm{N} 4)$ \\
\hline & & 5Pi $(E)=$ Peso PUAi do Município $M$; $(i=1 \ldots, N 5)$ \\
\hline
\end{tabular}

Por fim, após apuração do índice, foram feitas correlações entre o resultado do IGEM, o porte e a população de cada município. 


\section{Apresentação e Análise dos Dados}

A partir do processamento dos dados utilizados para elaboração do IGEM, foi possível verificar o índice de cada cidade que participou do estudo. Além disso, foram feitas análises específicas das práticas de governança eletrônica correlacionando de acordo com o porte de cada município.

Tabela 5

Índice de Governança Eletrônica dos Municípios Sergipanos

\begin{tabular}{|c|c|c|c|c|c|c|c|c|c|}
\hline Porte & Classificação & Cidade & População & Pcon & Pserv & PPC & PPS & PUA & IGEM \\
\hline \multirow{16}{*}{$\begin{array}{l}\text { M } \\
\text { É } \\
\text { D } \\
\text { I } \\
\text { O } \\
\text { S }\end{array}$} & $\begin{array}{l}1 \\
\end{array}$ & Lagarto & 96.602 & 10,478 & 6,667 & 6,666 & 5 & 13,335 & 42,146 \\
\hline & 2 & $\begin{array}{l}\text { Barra dos } \\
\text { Coqueiros }\end{array}$ & 26.059 & 3,81 & 5 & 1,818 & 6,666 & 13,335 & 30,629 \\
\hline & 3 & Boquim & 25.727 & 5,238 & 7,917 & 5,454 & 2,499 & 8,095 & 29,203 \\
\hline & 4 & Tobias Barreto & 48.776 & 6,665 & 6,25 & 0,606 & 4,167 & 8,094 & 25,782 \\
\hline & 5 & Itabaiana & 88.501 & 5,237 & 6,666 & 3,03 & 1,667 & 5,238 & 21,838 \\
\hline & 6 & Capela & 31.402 & 6,189 & 5 & 2,424 & 2,5 & 5,238 & 21,351 \\
\hline & 7 & Estância & 65.226 & 4,762 & 5,001 & 0,606 & 2,5 & 5,713 & 18,582 \\
\hline & 8 & Propriá & 28.612 & 2,856 & 4,166 & 1,212 & 2,5 & 7,618 & 18,352 \\
\hline & 9 & Poço Verde & 22.287 & 1,428 & 1,667 & 1,212 & 2,5 & 10,954 & 17,761 \\
\hline & 10 & Umbaúba & 23.223 & 3,333 & 3,333 & 0,606 & 0 & 8,571 & 15,843 \\
\hline & 11 & Itabaianinha & 39.432 & 3,332 & 4,999 & 0,606 & 0 & 6,666 & 15,603 \\
\hline & 12 & Itaporanga & 31.165 & 2,856 & 5,833 & 0 & 0,833 & 4,762 & 14,284 \\
\hline & 13 & Poço Redondo & 31.614 & 3,332 & 3,75 & 0 & 0,833 & 6,19 & 14,105 \\
\hline & 14 & Laranjeiras & 27.442 & 2,38 & 1,25 & 1,212 & 0 & 6,191 & 11,033 \\
\hline & 15 & Porto da Folha & 27.370 & 2,381 & 1,25 & 0,606 & 0 & 6,667 & 10,904 \\
\hline & 16 & Canindé & 25.733 & 1,429 & 2,918 & 0,606 & 0,833 & 4,286 & 10,072 \\
\hline & Classificação & Cidade & População & Pcon & Pserv & PPC & PPS & PUA & IGEM \\
\hline \multirow{13}{*}{$\begin{array}{l}P \\
E \\
Q \\
U \\
E \\
N \\
O \\
S\end{array}$} & 1 & Campo do Brito & 16.987 & 4,762 & 3,334 & 7,272 & 1,666 & 8,571 & 25,605 \\
\hline & 2 & Tomar do Gerú & 12.858 & 1,428 & 0,834 & 0 & 2,5 & 9,048 & 13,810 \\
\hline & 3 & Cristinápolis & 16.859 & 4,284 & 1,667 & 1,212 & 0 & 6,19 & 13,353 \\
\hline & 4 & Carmópolis & 14.130 & 1,904 & 2,5 & 1,212 & 1,667 & 5,714 & 12,997 \\
\hline & 5 & Riachão & 19.414 & 2,857 & 2,499 & 0,606 & 0 & 5,238 & 11,200 \\
\hline & 6 & Japoatã & 12.926 & 0 & 0,417 & 0 & 5 & 5,715 & 11,132 \\
\hline & 7 & Maruim & 16.478 & 3,333 & 0,833 & 1,212 & 0 & 4,761 & 10,139 \\
\hline & 8 & Pacatuba & 13.379 & 2,381 & 1,25 & 1,212 & 0 & 4,285 & 9,128 \\
\hline & 9 & Frei Paulo & 14.162 & 1,904 & 1,25 & 1,818 & 0 & 3,332 & 8,304 \\
\hline & 10 & Japaratuba & 17.213 & 1,904 & 0,834 & 1,212 & 0 & 4,286 & 8,236 \\
\hline & 11 & Neópolis & 18.493 & 1,904 & 1,667 & 0,606 & 0 & 3,81 & 7,987 \\
\hline & 12 & Moita Bonita & 11.038 & 1,428 & 0,833 & 0,606 & 0 & 3,333 & 6,200 \\
\hline & Classificação & Cidade & População & Pcon & Pserv & PPC & PPS & PUA & IGEM \\
\hline \multirow{13}{*}{$\begin{array}{l}M \\
\text { I } \\
C \\
R \\
O\end{array}$} & 1 & Arauá & 9.495 & 0 & 2,084 & 3,03 & 1,667 & 6,191 & 12,972 \\
\hline & 2 & Pedrinhas & 8.970 & 2,856 & 1,667 & 0,606 & 0 & 5,238 & 10,367 \\
\hline & 3 & Pirambu & 8.538 & 2,38 & 1,667 & 0 & 0 & 3,81 & 7,857 \\
\hline & 4 & Riachuelo & 9.509 & 1,428 & 1,25 & 0 & 0 & 4,762 & 7,440 \\
\hline & 5 & Siriri & 8.169 & 0,952 & 0,833 & 0 & 0 & 5,238 & 7,023 \\
\hline & 6 & Pinhão & 6.084 & 0,476 & 0,417 & 1,212 & 0 & 3,809 & 5,914 \\
\hline & 7 & São Miguel & 3.736 & 0,952 & 0,417 & 0 & 0 & 4,286 & 5,655 \\
\hline & 8 & $\begin{array}{c}\text { Santa Rosa de } \\
\text { Lima }\end{array}$ & 3.773 & 1,428 & 0 & 0 & 0 & 3,81 & 5,238 \\
\hline & 9 & Macambira & 6.492 & 0 & 0,833 & 0 & 0 & 4,285 & 5,118 \\
\hline & 10 & $\begin{array}{l}\text { Malhada } \\
\text { dos Bois }\end{array}$ & 3.494 & 0 & 0 & 0 & 2,5 & 2,381 & 4,881 \\
\hline & 11 & Divina Pastora & 4.487 & 1,905 & 0,834 & 0,606 & 0 & 1,428 & 4,773 \\
\hline & 12 & $\begin{array}{l}\text { N.S. de } \\
\text { Lourdes }\end{array}$ & 6.271 & 0 & 0 & 0,606 & 0 & 3,809 & 4,415 \\
\hline & - & MÉDIA & - & 2,654 & 2,490 & 1,242 & 1,187 & 5,857 & 13,431 \\
\hline
\end{tabular}

Fonte: Dados da pesquisa, 2013. 
Os resultados do IGEM foram organizados por porte dos municípios, conforme previsto na metodologia. Na tabela 5 tem-se o resultado, com o índice de cada subgrupo, com o ranking dos municípios em ordem decrescente, destacando em azul os maiores índices de cada prática para facilitar a visualização dos resultados.

Nota-se que no geral, os índices de governança dos municípios sergipanos são extremamente baixos. A média do IGEM dos municípios participantes da amostra é de 13,431. Isso mostra que, em média, apenas $13,4 \%$ das práticas de governança eletrônica estão implantadas nos municípios sergipanos.

O maior índice encontrado no estado de Sergipe foi na cidade de Lagarto (município da amostra com maior população), com 42,146 e o menor de 4,415, no município de Nossa Senhora de Lourdes (micro município).

Conforme se observa na tabela 5, os municípios com os melhores índices são os médios municípios. Os índices mais baixos estão justamente nos micro municípios. Aparentemente há uma influência do tamanho da população do município e o IGEM. Verifica-se que os municípios com maiores populações estão melhores classificados. Todavia, dentre as cinco cidades melhor classificadas está um pequeno município (Campo do Brito), com o 5 o melhor IGEM do Estado $(25,605)$.

Em uma análise intergrupos, depreende-se que os três primeiros classificados do grupo de pequenos municípios (Campo do Brito, Tomar do Gerú e Cristinápolis), bem como o primeiro colocado do grupo de micro municípios (Arauá) possuem IGEM melhor do que os três piores classificados do grupo de médios municípios, podendo ser considerados exceção a correlação entre população e IGEM.

Além da análise do IGEM geral, fez-se necessário destacar individualmente o nível de implantação das práticas de cada subgrupo.

Em relação às práticas de conteúdo, dos 20 pontos possíveis, verifica-se que o maior índice foi encontrado na cidade de Lagarto $(10,478)$. Entretanto, o maior destaque para esse subgrupo é o fato de 04 cidades apresentarem o índice 0 (zero). Ou seja, práticas bastantes simples tais como disponibilização de códigos e regulamentos do município e informações sobre órgãos com localização, telefones e horários de atendimentos não foram identificados.

Nas práticas de serviço, o maior índice encontrado foi na cidade de Boquim $(7,917)$. Neste portal foi identificado várias práticas relacionais como, por exemplo, o preenchimento de guias de impostos, taxas e multas e ainda, obtenção eletrônica de documentos tributários e consultas a certidões tributárias. A emissão de nota fiscal eletrônica foi a prática de serviços mais presente entre os portais de todos os grupos

Com relação às práticas de participação cidadã, uma pequena cidade (Campo do Brito), foi o que obteve a melhor pontuação. Foi possível identificar no portal deste município, informação sobre agenda de reuniões e calendário das discussões públicas, com incentivos a participação. Entretanto, chama a atenção o resultado dos micros municípios em que mais da metade deles (07) não possuem nenhuma prática de participação cidadã.

Os itens referentes as políticas de privacidade e segurança foram os que tiveram os piores índices. Em 22 municípios (55\% da amostra) não foi identificada nenhuma prática implementada (inclusive a responsabilidade pelas informações e atualizações do portal). Por outro lado, destaca o resultado positivo dos municípios de Barra dos Coqueiros com o índice de 6,66 e de Lagarto, 5,00. Conforme mostra a figura 2, o subgrupo de usuabilidade e acessibilidade foi o único em que, no conjunto, todos os municípios tiveram alguma prática identificada.

Assim, em relação aos subgrupos de práticas, verifica-se que a usuabilidade e acessibilidade (PUA) foram, no geral, as práticas mais identificadas $(5,857)$, seguido pelas práticas de conteúdo (PCon), com 2,654. As práticas de privacidade e segurança (PPS), juntamente com a participação cidadã (PPC) representaram as que foram identificadas em menor número, conforme se visualiza graficamente: 


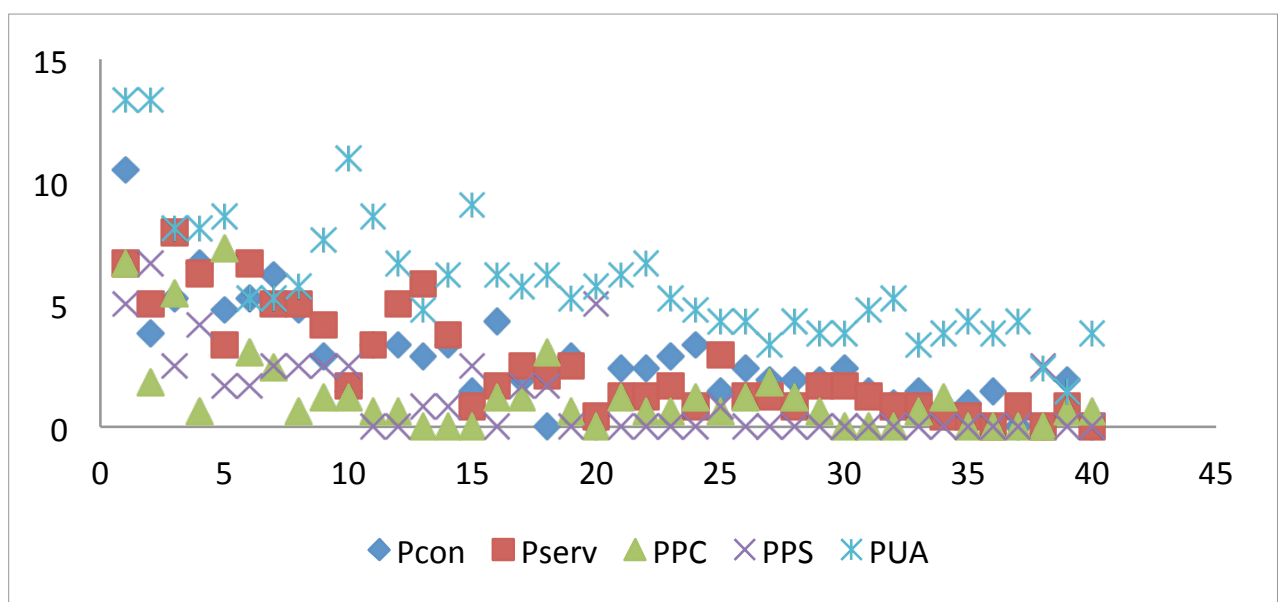

Figura 2 - Gráfico de Dispersão das práticas de cada subgrupo do IGEM Fonte: Dados da pesquisa, 2013

Em síntese, verifica-se que as práticas com os maiores índices estão relacionadas com questões técnicas (usuabilidade e acessibilidade) em detrimento das práticas de prestação de serviços públicos e participação cidadã (que obteve em muitos municípios índices nulos).

\section{Considerações Finais}

Os órgãos públicos tem utilizado cada vez mais a internet para disponibilização de informações, prestação de serviços públicos e promoção da participação cidadã em busca de uma boa governança. Assegurar que essas funções estejam disponíveis para todos os cidadãos é determinante para que a popularização do acesso ao Estado seja efetivo também nos meios virtuais.

Nesse contexto, este artigo objetivou verificar os índices de governança eletrônica nos municípios do Estado de Sergipe. Para isso, a partir da proposta metodológica de Mello e Slomski (2010), propôs-se identificar as práticas de governança eletrônica nos websites de tais municípios.

Os resultados apontaram índices de governança eletrônica nas administrações municipais extremamente baixos, com uma média entre os municípios participantes da pesquisa de 13,413, em uma escala de 0 a 100. Observa-se, portanto, que a quantidade de medidas de governança eletrônica que já foram implantadas pelas prefeituras municipais ainda é muito limitada. Todavia, o valor do IGEM apurado na cidade de Lagarto $(42,146)$, município com o maior índice encontrado, foi maior do que o índice dos Estados de Rondônia e Mato Grosso do Sul apurados na pesquisa de Mello e Slomski (2010).

$\mathrm{Na}$ análise das práticas de governança dos portais municipais sob a ótica do porte dos municípios, verificou-se que metade $(6,0)$ dos micro municípios obtiveram taxas muito menores do que a média estadual (entre 4,4 e 6,0). Sobressaem os sites municipais com pequena capacidade, com caráter apenas informativo, o que demonstra a necessidade do investimento na implementação de políticas de governança.

Dentre os pequenos municípios a realidade não é destoante dos micros municípios. Neste grupo pedromina os municípios com IGEM entre 6,20 a 13,81 , resultado pouco melhor do que encontrado nos micro municípios. Todavia, o perfil dos portais destes municípios é semelhante ao grupo anterior. Prevalece o caráter informativo institucional com raras possibilidades de interação ou participação cidadã.

O grupo dos médios municípios obteve os resultados mais significativos, todavia, ainda muito longe do ideal. Afinal, apenas um município obteve índice acima de 40 pontos. Ademais, mais da metade (10) dos municípios desse grupo obtiveram índices menores que 20. Outrossim, mesmo esse grupo apresentando pequenos avanços em relação aos de pequenos e micros municípios, poucas foram as práticas encontradas que permitem uma maior participação dos cidadãos. De qualquer forma, nesse grupo, foi possível identificar algumas práticas que permitem uma maior interação entre o governo e sociedade, fator chave para promoção de uma boa governança.

Entretanto, os resultados da pesquisa podem ser vistos de outro ângulo. Conforme analisa Pinho (2008) pode-se considerar, devido ao porte dos municípios apontados na pesquisa, que esses governos ainda não têm condições de incorporar toda uma nova cultura de utilização das TICs, ou 
seja, não estão devidamente preparados para esse novo período, ou que, talvez, estejam ainda em construção. Ademais, só o fato desses governos estarem presentes na internet já representa um avanço, visto que, do universo da pesquisa, $37 \%$ das prefeituras municipais do estado de Sergipe sequer estão presentes na rede.

De maneira geral, percebeu-se que muitas das práticas não identificadas podem ser facilmente resolvidas e que, na maioria das vezes, requer pequenos esforços das administrações, como é o caso das práticas de conteúdo e de prestação de serviços. Grande parte dos sites ainda não disponibiliza um portal de acesso às informações públicas, o que faz acreditar que a Lei 12.527 (2011) ainda não causou o efeito desejado na esfera municipal.

Isto posto, sugere-se a adoção de práticas simples como disponibilizar uma lista de links de órgãos internos e externos, com a localização dos setores, contato com horário de funcionamento, endereço, e responsáveis; disponibilizar um calendário de eventos da comunidade, fornecer um quadro de anúncios/informativos da prefeitura, disponibilizar fóruns de discussão para diálogo entre o governo e a comunidade, e, ainda disponibilizar um portal de acesso as informações públicas; ou simplesmente, disponibilizar as notícias e informações sobre políticas públicas, o que ainda não é encontrado em diversos portais.

Em outra análise, o estudo indica que ainda há pouca preocupação com as práticas relacionadas à participação cidadã. Os melhores resultados dos municípios foram apurados nas práticas de usuabilidadee acessibilidade. Constata-se, que em fatores técnicos e operacionais os resultados podem ser considerados positivos. Porém, isso leva a acreditar, conforme analisaram Raupp e Pinho (2012), Laia, Cunha, Nogueira \& Mazzon (2011) que a tecnologia já existe, mas ainda não é utilizada com o objetivo de interação entre o cidadão e o ente governamental. Fato é que se vivencia um processo ainda lento de construção da governança eletrônica, principalmente na esfera municipal como foi evidenciado por este estudo.

Em relação às limitações deste estudo, destaca-se que os dados coletados empiricamente representam a situação do período da pesquisa. Assim, diversas práticas de governança eletrônica já podem ter sido implementadas pelas administrações municipais. Outrossim, esse estudo ficou restrito as administrações públicas no âmbito do executivo, não abordando outras esferas de atuação governamental.

Algumas contribuições foram trazidas à tona. A primeira diz respeito à contribuição do estudo para a temática da Governança Eletrônica devido à escassez de pesquisas relacionadas à governança pública. A segunda refere-se ao cenário pesquisado e a sua operacionalização mediante coleta de dados em fontes públicas, permitindo uma replicação em futuras pesquisas. A terceira está relacionada com a tentativa de preencher uma lacuna teórica ao desenvolver o estudo nos micro, pequenos e médios municípios. E por fim, o estudo traz uma contribuição prática para os gestores públicos municipais ao fornecer possibilidades de melhoria nas políticas de Governança Eletrônica, e, consequentemente na expansão da participação democrática e melhor prestação de serviços aos cidadãos.

Há de ressaltar que os resultados obtidos podem ser utilizados para futuras pesquisas que busquem revelar determinantes para os níveis de adoção do IGEM dos governos locais, ademais, a metodologia utilizada pode ser adotada como padrão por institutos de pesquisa para monitorar o índice de governança, expandindo, por exemplo, o método que já é utilizado pelo IBGE. Em síntese, o estudo fornece ainda perspectivas empíricas que podem estabelecer comparações analíticas ou mesmo a confirmação (e aprofundamento) dos resultados com o uso de metodologias de caráter qualitativo, permitindo uma ampliação da discussão da temática, uma vez que novos elementos de análise sobre práticas de governança eletrônica podem surgir ratificando o entendimento de que há uma relevância teórica e prática nas publicações no campo de governança pública.

\section{Referências}

Alexandrini, F, Piske, Ingobert, \& Piske, Ricardo (2006). Prefeitura Virtual: a Internet a Serviço da Comunidade. Gestão \& Regionalidade, 22(65), 1-9.

Araújo, R. M. de, Araújo, M. A. D., Alloufa, J. M. L., \& Lopes, A. O. B. (2013). Governo Eletrônico: um estudo sobre as possibilidades de participação do cidadão. Informação \& Sociedade, 23(1), 73-90.

Araújo, W. F. G., \& Laia, M. M. (2004, setembro). Governança eletrônica e gestão da informação em portais de governo: uma análise da reestruturação do Portal Minas. Anais do Encontro Nacional da Associação Nacional de Pós-Graduação e Pesquisa em Administração, Curitiba, PR, Brasil, 28. 
Beuren, I. M., Moura, G.D. de, \&Kloeppel, N. R. (2013). Práticas de governança eletrônica e eficiência na utilização das receitas: uma análise nos estados brasileiros. Revista de Administração Pública, (47), 2, 421-441.

BRASIL. Lei no 12.527, de 18 de novembro de 2011, de 5 de maio de 2005. Recuperado em 25 de Maio, 2013, de <http://www.planalto.gov.br/ccivil_03/_ato2011-2014/2011/lei/l12527.htm>.

Castells, Manuel. (1999). An Introduction to the Information Age. InMackay, H., \& O'sullivan. The Media Reader: Continuity and Transformation, London: Sage.

Collis, J., \& Hussey, R. (2005). Pesquisa em Administração (2ª ed.). Porto Alegre: Bookman.

Cordeiro, A., Martins, C.S.F., Santos, N. B. dos, Ribeiro, R. V., \& Petra, T. (2012). Governo eletrônico e redes sociais: informação, participação e interação. RECISS, 6(2).

Cunha, M. A. V. C. da, Frega, J. R., \& Lemos, I. S.(2011). Portais de serviços públicos e de informação ao cidadão no Brasil: uma descrição do perfil do visitante. Revista Eletrônica de Sistemas de Informação, 10(1).

Diniz, E. H., Barbosa, A. F., Junqueira, A. R. B., \& Prado, O. (2009). O governo eletrônico no Brasil: perspectiva histórica a partir de um modelo estruturado de análise. Revista de Administração Pública, 43(1), 23-48.

Ferrer, F., \& Santos, P. (2004). E-Government: o governo eletrônico no Brasil. São Paulo: Saraiva.

Frey, K. (2002). Governança eletrônica: experiências de cidades europeias e algumas lições para países em desenvolvimento. In: EISENBERG, J., \& CEPIK, M. (org.) Internet e política: teoria e prática da democracia eletrônica. Belo Horizonte: UFMG, 141-163.

Funai, M. T., \& Rezende, D. A. (2011). Governo eletrônico na gestão municipal: avaliação dos serviços eletrônicos da prefeitura de São José dos Pinhais (PR). Gestão \& Regionalidade, 27(80).

Hilgers, D., \& Piller F. (2011). A Government 2.0: Fostering Public Sector Rethinking by Open Innovation. Innovation Management.

Holzer, M, \& Kim, S-T. (2005). Digital governance in municipalities worldwide: a longitudinal assessment of municipal websites throughout the world. Division for Public Administration and Development Management Department of Economic and Social Affairs, United Nations.

IBGE - Instituto Brasileiro de Geografia e Estatística (2012a). Perfil dos municípios brasileiros: pesquisa de informações básicas municipais2012. Rio de Janeiro: IBGE.

IBGE - Instituto Brasileiro de Geografia e Estatística (2012b). Estimativas de população em 2012. Recuperado em 10 Junho, 2013, de

<http://www.ibge.gov.br/home/estatistica/populacao/estimativa2012/estimativa_tcu.shtm>

Jaeger-Neto, J. I., Becker, C. A., Luciano, E. M., Testa, M. G. (2009). A percepção dos gestores de TI em relação às práticas de governançade $\mathrm{TI}$ adotadas em empresas do Rio Grande do Sul. Revista Eletrônica de Sistemas de Informação,8(1), 1-18.

Janowski, T., Pardo, T. A., \& Davies, J. (2012). Government information networks: map- ping electronic governance cases through public administration concepts. Government Information Quarterly, 29, S1-S10.

Klering, L.R., \& Schröeder, C. da S.(2008). Níveis de virtualização de sites de governos municipais. Análise, 19(2).

Laia, M. M. D., Cunha, M. A. V. C. D., Nogueira, A. R.R., \& Mazzon, José Afonso. (2011). Electronic government policies in Brazil: context, ICT management and outcomes. Revista de Administração de Empresas, 51(1), 43-57.

Lastres, H. M.M., \& Albagli, S. (1999). Chaves para o terceiro milênio na era do conhecimento. In Lastres, H.M.M., \& Albagli, S. (Org.). Informação e globalização na era do conhecimento. Rio de Janeiro: Campus.

Lastres, H.M.M., Ferraz, J. C.(1999). Economia da informação, do conhecimento e do aprendizado. In Lastres, H.M.M., \& Albagli, S. (Org.). Informação e globalização na era do conhecimento. Rio de Janeiro: Campus.

Medeiros, P. H. R., \& Guimarães, T. de A. (2005). A relação entre governo eletrônico e governança eletrônica no governo federal brasileiro. Cadernos Ebape.Br, 4, 1-18. 
Mello, G. R. (2009). Estudo das práticas de governança eletrônica: instrumento de controladoria para a tomada de decisões na gestão dos estados brasileiros. Tese de doutorado, Universidade de São Paulo, São Paulo, Brasil.

Mello, G.R. de, \& Slomski, V. (2010). Índice de governança eletrônica dos estados Brasileiros (2009): no âmbito do poder executivo. Journal of Information Systems and Technology Management, 7(2), p. 375-408.

Neuman, L. W. (1997). Social Research Methods: Qualitative and Quantitative Approaches. 3. ed. Boston: Allyn \& Bacon.

Pinho, J. A. G. de. (2008). Investigando portais de governo eletrônico de estados no Brasil: muita tecnologia, pouca democracia. Revista de Administração Pública, 42(3), 471-93.

Raupp, F. M., \& Pinho, J. A. G. de. (2012). Possibilidades de Participação no Legislativo Municipal por meio de Portais Eletrônicos. Cadernos Gestão Pública e Cidadania, 17(61).

Rezende, D. A. (2007). Planejamento de informações públicas municipais: sistemas de informação e de conhecimento, informática e governo eletrônico integrados aos planejamentos das prefeituras e municípios. Revista de Administração Pública, 41(3), 505-536.

Ruediger, M. A. (2002). Governo eletrônico ou governança eletrônica-conceitos alternativos no uso das tecnologias de informação para o provimento de acesso cívico aos mecanismos de governo e da reforma do Estado. Anais do Congresso del CLAD, Caracas, Venezuela.

Sampaio, R. C. (2010). Governança eletrônica no Brasil: limites e possibilidades introduzidos pelo Orçamento Participativo na Internet. Planejamento e Políticas Públicas.

Santana Junior, J. J. B. D, Libonati, J. J., Vasconselos, M. T. C., \& Slomski, V. (2009). Transparência fiscal eletrônica: uma análise dos níveis de transparência apresentados nos sites dos poderes e órgãos dos Estados e do Distrito Federal do Brasil. Revista de Educação e Pesquisa em Contabilidade, $3(3), 62-84$.

Torres, N. A., \& Agune, R. M. (2009). Web-gov nos municípios paulistas. PoliTiCs. Núcleo de Estudos, Pesquisa e Formação da RITS, (3), disponível em

http://www.politics.org.br/sites/default/files/poliTiCS_n3_NorbertoTorres-RobertoAgune.pdf 
Apêndice I

Apêndice I - Dimensões e variáveis do Índice de Governança Eletrônica dos Municípios

\begin{tabular}{|c|c|}
\hline VARIÁVEIS & PRÁTICAS DE CONTEÚDO (PCon) \\
\hline PCon 1 & $\begin{array}{l}\text { Disponibilizar uma lista de links de órgãos internos e externos, a localização dos escritórios, } \\
\text { agências, setores etc., contato com horário de funcionamento, endereço, nomes etc. }\end{array}$ \\
\hline PCon2 & Disponibilizar a agenda do gestor e das políticas da instituição. \\
\hline PCon3 & Disponibilizar os códigos e regulamentos do Município. \\
\hline PCon4 & $\begin{array}{l}\text { Disponibilizar as informações do orçamento, relatórios contábeis, anexos da LRF, informações } \\
\text { das licitações em andamento, editais etc. }\end{array}$ \\
\hline PCon5 & Disponibilizar as informações sobre os cargos, competências e salários dos servidores. \\
\hline PCon6 & Disponibilizar as informações sobre concursos públicos, editais, gabaritos de provas etc. \\
\hline PCon 7 & Permitir a cópia de documentos públicos, por meio de impressão, download etc. \\
\hline PCon 8 & $\begin{array}{l}\text { Os documentos públicos devem ter referências corretas, ausência de erros de digitação, grafia } \\
\text { ou gramática; identificação da propriedade intelectual, identificação das fontes ou dos } \\
\text { responsáveis, meios de estabelecer contato; conteúdo em linguagem clara, tom profissional, } \\
\text { ausência de preconceitos no discurso e informação livre de publicidade. }\end{array}$ \\
\hline PCong & $\begin{array}{l}\text { Disponibilizar informações sobre a gestão de emergências, utilizando o site como um } \\
\text { mecanismo de alerta para problemas naturais ou provocados pelo homem. }\end{array}$ \\
\hline PCon 10 & $\begin{array}{l}\text { Publicar as ofertas de empregos, de treinamento e recursos de encaminhamento de currículo } \\
\text { por interessados. }\end{array}$ \\
\hline PCon 11 & $\begin{array}{l}\text { Disponibilizar um calendário de eventos da comunidade, um quadro de anúncios/informativos } \\
\text { etc. }\end{array}$ \\
\hline PCon 12 & $\begin{array}{l}\text { Disponibilizar informações com atribuição de responsabilidade formal pelo conteúdo e pela } \\
\text { atualização das páginas. }\end{array}$ \\
\hline PCon13 & $\begin{array}{l}\text { Disponibilizar em seu site os arquivos de áudio e vídeo de eventos públicos, palestras, } \\
\text { encontros etc. }\end{array}$ \\
\hline PCon 14 & $\begin{array}{l}\text { Disponibilizar em seu site link para redes sociais (facebook, twitter, etc.) da Prefeitura e/ou dos } \\
\text { Governantes. }\end{array}$ \\
\hline VARIÁVEIS & PRÁTICAS DE SERVIÇOS (PServ) \\
\hline PServ1 & Disponibilizar e-mails, telefones e endereços para solicitar informações. \\
\hline PServ2 & A página principal deve ser personalizada para facilitar o acesso do cidadão aos serviços. \\
\hline PServ3 & $\begin{array}{l}\text { Permitir o acesso a informações privadas utilizando senhas, como em registros educacionais, } \\
\text { médicos, cadastro civil etc. }\end{array}$ \\
\hline PServ4 & $\begin{array}{l}\text { Permitir o acesso a informações relacionadas à educação, indicadores econômicos, instituições } \\
\text { educacionais, meio ambiente, saúde, transporte etc. }\end{array}$ \\
\hline PServ 5 & Identificar o responsável ou gerenciador do site para possível contato ou responsabilização. \\
\hline PServ6 & Disponibilizar um relatório das violações de leis e regulamentos administrativos municipais. \\
\hline PServ 7 & Disponibilizar um mecanismo para submissão, monitoramento de queixas/denúncias públicas. \\
\hline PServ8 & Disponibilizar as notícias e informações sobre políticas públicas. \\
\hline PServ9 & $\begin{array}{l}\text { Permitir o preenchimento de guias de impostos, taxas, contribuições de melhorias, multas etc. } \\
\text { Essa prática deve permitir o acesso a informações, cálculo do tributo e possível multa e juros. }\end{array}$ \\
\hline PServ10 & Permitir o pagamento on-line de impostos, taxas, contribuições de melhorias, multas, etc. \\
\hline PServ11 & Publicar os editais de abertura de licitações e seus respectivos resultados. \\
\hline PServ12 & $\begin{array}{l}\text { Permitir a obtenção eletrônica de documentos tributários, como: consultas e certidões } \\
\text { tributárias, nota fiscal eletrônica etc. }\end{array}$ \\
\hline PServ13 & Permitir o registro do cidadão e/ou empresa para serviços on-line. \\
\hline PServ 14 & $\begin{array}{l}\text { Conceder licenças, registros ou permissões, como: licenças, registros, permissão e alvará para } \\
\text { construção etc. }\end{array}$ \\
\hline PServ15 & Permitir inscrição e/ou a compra de bilhetes para eventos públicos etc. \\
\hline PServ16 & as me uiante a reamzaçau ve preyau \\
\hline
\end{tabular}


Continuação...

\begin{tabular}{|c|c|}
\hline VARIÁVEIS & PRÁTICAS DE PARTICIPAÇÃO CIDADÃ (PPC) \\
\hline PPC1 & sssuir um boletim informativo on-line. \\
\hline PPC2 & sponibilizar informações de governança. \\
\hline PPC3 & $\begin{array}{l}\text { Disponibilizar um e-mail para contato, com a descrição da política adotada de resposta, } \\
\text { começando com o tempo e a data de recepção, o prazo estimado para a resposta, o que fazer } \\
\text { se a resposta não for recebida e uma cópia da sua mensagem original. }\end{array}$ \\
\hline PPC4 & $\begin{array}{l}\text { Disponibilizar um quadro de anúncios, bate-papo, fórum de discussão, grupos de discussão, } \\
\text { chats, etc. }\end{array}$ \\
\hline PPC5 & $\begin{array}{l}\text { Disponibilizar a agenda de reuniões ou calendário das discussões públicas, incluindo o tempo, } \\
\text { lugar, agenda e informações sobre os depoimentos dos cidadãos, participação, observação ou } \\
\text { opções. }\end{array}$ \\
\hline PPC6 & $\begin{array}{l}\text { Fazer pesquisas ou sondagens, breves ou mais detalhadas, de satisfação, opinião, } \\
\text { manifestação de preferências e sugestões, para verificar a percepção do cidadão quanto aos } \\
\text { serviços prestados e à própria estrutura de governança eletrônica. }\end{array}$ \\
\hline PPC7 & sponibilizar um canal específico para encaminhamento de denúncias. \\
\hline PPC8 & $\begin{array}{l}\text { Disponibilizar informações biográficas, e-mail, telefone, fotografia, endereço para contato com } \\
\text { os gestores eleitos e membros do governo. }\end{array}$ \\
\hline PPC9 & Disponibilizar a estrutura e as funções do governo. \\
\hline PPC10 & $\begin{array}{l}\text { Disponibilizar um link específico para "democracia" ou "participação cidadã" na página } \\
\text { principal do seu site, permitindo ligações com a legislação, orçamento e outros detalhes de } \\
\text { informação de accountability. }\end{array}$ \\
\hline PPC11 & isponibilizar um portal de acesso a informação. \\
\hline VARIÁVEIS & PRÁTICAS DE PRIVACIDADE E SEGURANÇA (PPS) \\
\hline PPS 1 & $\begin{array}{l}\text { Declarar a política de privacidade no site, descrevendo os tipos de informações recolhidas e as } \\
\text { políticas de utilização e partilha das informações pessoais, identificando os coletores das } \\
\text { informações, disponível em todas as páginas que aceitam os dados, e com a data em que a } \\
\text { política de privacidade foi revisada. }\end{array}$ \\
\hline PPS 2 & $\begin{array}{l}\text { Permitir diminuir a divulgação de informações pessoais, dispondo da possibilidade de entrar e } \\
\text { sair do fornecimento das informações. }\end{array}$ \\
\hline PPS 3 & $\begin{array}{l}\text { Permitir que o usuário revise os dados pessoais e conteste os registros de informações } \\
\text { incompletas ou erradas. }\end{array}$ \\
\hline PPS 4 & $\begin{array}{l}\text { Informar as práticas antes de qualquer informação pessoal ser coletada, evidenciando a } \\
\text { entidade que está obtendo a informação, o propósito do recolhimento, potenciais recebedores, } \\
\text { natureza da informação, meios de coleta, se as informações são voluntárias ou obrigatórias e } \\
\text { consequência do não fornecimento. }\end{array}$ \\
\hline PPS 5 & $\begin{array}{l}\text { Limitar o acesso de dados e garantir que não será utilizado para fins não autorizados, utilizando } \\
\text { senhas e criptografia de dados sensiveis e procedimentos de auditoria. }\end{array}$ \\
\hline PPS 6 & $\begin{array}{l}\text { Disponibilizar um endereço de contato, telefone e/ou e-mail, específicos para denúncias, } \\
\text { críticas etc., sobre a política de privacidade e segurança. }\end{array}$ \\
\hline PPS 7 & $\begin{array}{l}\text { Permitir o acesso a informações públicas por meio de uma área restrita que exija senha e/ou } \\
\text { registro, como o uso de assinatura digital para identificar os usuários. }\end{array}$ \\
\hline PPS 8 & $\begin{array}{l}\text { Permitir o acesso a informações não públicas para os servidores mediante uma árearestrita que } \\
\text { exija senha e/ou registro. }\end{array}$ \\
\hline VARIÁVEIS & PRÁTICAS DE USUABILIDADE E ACESSIBILIDADE (PUA) \\
\hline PUA1 & $\begin{array}{l}\text { Fornecer um link para informações sobre o governo, com a possibilidade de contato, com } \\
\text { endereço, telefone, fax ou e-mail. }\end{array}$ \\
\hline PUA2 & $\begin{array}{l}\text { Determinar o público-alvo do site, com canais personalizados para grupos específicos, como } \\
\text { cidadãos, empresas ou outros órgãos públicos. }\end{array}$ \\
\hline PUA3 & $\begin{array}{l}\text { A barra de navegação deve ter os itens agrupados na área de navegação, termos claros } \\
\text { utilizados para definir as opçães de navegação de categorias, ícones de navegação de } \\
\text { reconhecimento imediato da classe de itens, links identificados etc. }\end{array}$ \\
\hline PUA4 & $\begin{array}{l}\text { Fornecer links clicáveis para a página inicial em todas as páginas, para os departamentos } \\
\text { governamentais e para sites relacionados fora do governo }\end{array}$ \\
\hline & Disponibilizar na página principal um mapa do site ou esboço de todos os sites. \\
\hline PUA6 & Disponibilizar a data da última atualização das páginas. \\
\hline PUA7 & Disponibilizar versões alternativas de documentos longos, como em .pdf ou .doc. \\
\hline PUA8 & $\begin{array}{l}\text { Permitir que os campos dos formulários sejam acessíveis por meio das teclas ou do cursor; } \\
\text { identificando, claramente, aqueles com preenchimentos obrigatórios }\end{array}$ \\
\hline
\end{tabular}


Continuação..

\begin{tabular}{|c|c|}
\hline VARIÁVEIS & PRÁTICAS DE USUABILIDADE E ACESSIBILIDADE (PUA) \\
\hline PUA9 & Disponibilizar informações de como identificar e corrigir erros submetidos. \\
\hline PUA10 & Dispor de um site de busca ou um link no próprio site do governo. \\
\hline PUA11 & $\begin{array}{l}\text { Dispor de seu próprio mecanismo de pesquisa, permitindo que as pesquisas sejam feitas de } \\
\text { forma específica, por secretaria, em todo o site etc. }\end{array}$ \\
\hline PUA12 & Disponibilizar um mecanismo de acesso aos portadores de necessidades especiais. \\
\hline PUA13 & $\begin{array}{l}\text { O conteúdo do site é disponível para ser acessado de dispositivos móveis (tablets, } \\
\text { smartphones, etc.) }\end{array}$ \\
\hline PUA14 & Permitir o acesso ao site e seus conteúdos por meio do teclado do computador \\
\hline
\end{tabular}

Fonte: adaptado de Mello e Slomski (2010). 